\title{
Gonococcal outer-membrane protein PIB: comparative sequence analysis and localization of epitopes which are recognized by type-specific and cross-reacting monoclonal antibodies
}

\author{
N. J. Butt, ${ }^{1} \dagger$ M. VirJi, ${ }^{1} \ddagger$ F. Vayreda,${ }^{2}$ P. R. Lambden ${ }^{1}$ and J. E. Heckels ${ }^{1 *}$ \\ ${ }^{1}$ Department of Microbiology, Southampton University Medical School, Southampton General Hospital, Tremona Road, \\ Southampton SO9 $4 X Y, U K$ \\ ${ }^{2}$ Biokit SA, Corcega 603, 08025 Barcelona, Spain
}

(Received 29 May 1990; revised 17 July 1990; accepted 25 July 1990)

\begin{abstract}
Comparison of the inferred amino acid sequence of outer-membrane protein PIB from gonococcal strain P9 with those from other serovars reveals that sequence variations occur in two discrete regions of the molecule centred on residues 196 (Var1) and 237 (Var2). A series of peptides spanning the amino acid sequence of the protein were synthesized on solid-phase supports and reacted with a panel of monoclonal antibodies (mAbs) which recognize either type-specific or conserved antigenic determinants on PIB. Four type-specific mAbs reacted with overlapping peptides in Var1 between residues 192-198. Analysis of the effect of amino acid substitutions revealed that the mAb specificity is generated by differences in the effect of single amino acid changes on mAb binding, so that antigenic differences between strains are revealed by different patterns of reactivity within a panel of antibodies. The variable epitopes in Var1 recognized by the type-specific mAbs lie in a hydrophilic region of the protein exposed on the gonococcal surface, and are accessible to complement-mediated bactericidal lysis. In contrast, the epitope recognized by mAb SM198 is highly conserved but is not exposed in the native protein and the antibody is non-bactericidal. However, the conserved epitope recognized by mAb SM24 is centred on residues 198-199, close to Var1, and is exposed for bactericidal killing.
\end{abstract}

\section{Introduction}

Protein I (PI) is the most abundant protein present on the surface of Neisseria gonorrhoeae and, unlike several other major surface antigens, does not undergo antigenic shift during infection (Zak et al., 1984). PI appears to be essential for gonococcal viability, occurring in the outer membrane as a trimer which functions as an anionselective porin and allows uptake of essential nutrients (Young et al., 1983; Lynch et al., 1983). In addition to its

$\dagger$ Present address: School of Biological Sciences, University of Sussex, Brighton, UK.

$\ddagger$ Present address: University Department of Paediatrics, John Radcliffe Hospital, Oxford, UK.

Abbreviations: mAb, monoclonal antibody; PCR, polymerase chain reaction.

The complete nucleotide sequence of the por gene from strain $\mathrm{P} 9$ and the partial sequences of the other strains have been submitted to the GenBank/EMBL database and have been assigned the accession numbers X52823-X52827. porin activity, PI may play an important role in the pathogenesis of gonococcal infection, since in vitro studies have shown that, on contact, it may be transferred from the gonococcal outer membrane into the cell membrane of eukaryotic cells. Such a process may play a crucial role in gonococcal interaction with host cells in vivo (Blake, 1985). Antibodies directed against PI have been shown to be opsonic for phagocytosis by polymorphonuclear leucocytes, to promote complement-mediated bactericidal killing and to inhibit gonococcal damage to epithelial cells (Virji et al., 1986, 1987). For these reasons $P I$ is of considerable interest as a potential component of a gonococcal vaccine.

Although expression of PI is stable within a strain, differences occur between strains which are responsible for antigenic diversity. Thus, immunization with native PI results in the production of antibodies having limited reactivity with heterologous strains (Heckels et al., 1989). Biochemical and immunological studies have revealed two major classes of PI (PIA and PIB); these can be further subdivided into a number of different serovars (Sandstrom et al., 1982; Knapp et al., 1984). 
Antigenic analysis of PI has been aided by the use of monoclonal antibodies (mAbs). Differences in the pattern of reactivity of gonococcal strains with panels of mAbs have been utilized to define serovars of both PIAand PIB-expressing strains (Knapp et al., 1984; Sandstrom et al., 1985). In our previous studies, a panel of mAbs was used to investigate the immunochemistry of PIB and the potential protective effect of antibodies directed against different PIB epitopes (Fletcher et al., 1986; Virji et al., 1986). Although the majority of mAbs obtained demonstrated restricted reactivity among the panel of strains tested, one antibody (SM24) was obtained which recognized $92 \%$ of PIB-expressing strains (Fletcher et al., 1986). In in vitro studies $\mathrm{mAb}$ SM24 was opsonic, bactericidal and prevented cell damage, revealing the presence of a protective, but immunorecessive, conserved determinant on PIB. Such determinants represent attractive targets for vaccination.

Knowledge of the structure of the PIB molecule is therefore of considerable importance in attempting to identify both the conserved epitopes with vaccine potential and the variable epitopes responsible for serovar differences between strains. The nucleotide sequences of the genes (por) responsible for PIB expression in two strains have been determined (Gotschlich et al., 1987; Carbonetti et al., 1988). Despite antigenic differences between the strains R10 and MS11, the inferred amino acid sequences show extensive homology, suggesting that limited structural variations may be responsible for generating antigenic diversity. In this paper we report the inferred amino acid sequence of PIB from strain P9, the immunobiology of which has been extensively studied (Heckels, 1977; Lambden \& Heckels, 1979; Virji et al., 1986; Heckels et al., 1989, 1990), and demonstrate that sequence variations occur between a number of other serovars in two discrete regions of the PIB molecule. In addition, we have used the sequence information to construct synthetic peptides and map the epitopes recognized by both the typespecific and cross-reacting, protective, anti-PIB mAbs.

\section{Methods}

Bacterial strains and growth conditions. Gonococci were grown on proteose peptone agar at $37^{\circ} \mathrm{C}$ in $5 \%(\mathrm{v} / \mathrm{v}) \mathrm{CO}_{2}$. Strain P9-17 $\left(\mathrm{Pil}^{+} \mathrm{PII}^{+}\right.$) has been described previously (Lambden \& Heckels, 1979); strains SU50, SU75, SU85 and SU97 were local isolates (Zak et al., 1984). Strain R10 was obtained from Professor E. C. Gotschlich, Rockefeller University, New York, USA, and strain MS11 was from Professor F. Sparling, University of North Carolina, USA. Serovar determination was done by $\mathrm{Dr}$ C. Ison, St Mary's Hospital Medical School, UK.

$m A b s$. mAbs SM20, SM21, SM22 and SM24, which react with PIB from a number of gonococcal strains, were obtained following sequential immunization of mice with outer membranes from a variety of strains as described in detail previously (Virji et al., 1986; Fletcher $e t$ al., 1986). mAbs SM198 and SM203 were obtained subsequently using similar protocols after immunization of mice with outer membranes of strain P9 which had first been extracted with sodium cholate (Heckels, 1977).

The reactivity of mAbs with gonococcal strains was determined by 'dot blotting' (Virji et al., 1987); antibody binding was detected with ${ }^{125}$ I-protein A or goat anti-mouse IgG-alkaline phosphatase conjugate (Zymed) using AP colour development reagents (Bio-Rad) as substrates.

Sequence analysis of PIB. The complete nucleotide sequence of the por gene encoding expression of PIB in strain P9 has been determined (Butt et al., 1990). This information was used to obtain the sequences of variable regions from other strains of gonococci using material generated by the polymerase chain reaction (PCR). Crude chromosomal DNA preparations were amplified using two primers spanning the region of interest: primer 17, GAATTCAAGCTT${ }^{570}$ AACTACCAAAACAGCGGCTTCTTCG ${ }^{594}$; and primer 18 , GTCGACCTGCAG-832 ${ }^{8 C G G T A G C G G C A A C T T C G G T ~}{ }^{813}$ (underlined regions show additional bases carrying restriction sites used for subsequent cloning). Reactions were carried out in a Perkin-Elmer Cetus thermal cycler and subjected to 25 cycles of amplification. The cycle times were as follows: annealing, $2 \mathrm{~min}$ at $37^{\circ} \mathrm{C}$; primer extension, $3 \mathrm{~min}$ at $72{ }^{\circ} \mathrm{C}$; denaturation, $1 \mathrm{~min}$ at $94^{\circ} \mathrm{C}$. On the last cycle the denaturation step was omitted and the extension step increased to $10 \mathrm{~min}$. PCR-amplified material was digested with HindIII and PstI and purified by agarose gel electrophoresis. The desired fragments were excised from the gel, purified by Geneclean (Bio 101) and cloned into M13mp18 or M13mp19. For each gonococcal variant templates were prepared from 10 recombinant phage, pooled and subjected to sequence analysis using dideoxy chain termination and deoxyadenosine $5^{\prime}-\alpha-\left[{ }^{35}\right.$ S $]$ thiotriphosphate.

Computer analysis of the predicted protein secondary structure was done using the SERC, SEQNET node at Daresbury, UK, using the algorithms of Kyte \& Doolittle (1982) and Hopp \& Woods (1981). Multiple sequence alignment was done using the CLUSTALL algorithm (Higgins \& Sharp, 1988).

Solid-phase peptide synthesis. This was done using a commercially available kit (Cambridge Research Biochemicals) in which peptides are synthesized onto polyethylene rods (Geysen et al., 1987). Synthesis was done as described previously (Virji \& Heckels, 1989) using pentafluorophenyl active esters of fluorenylmethoxycarbonyl-L-amino acids with t-butyl side-chain-protecting groups (Pfp-FMOC amino acids, Milligen), except in the case of methionine which had a trimethylsulphonyl side-chain-protecting group and serine and threonine in which the oxybenzotriazine active ester was used. After peptides of the desired length had been synthesized the terminal amino group was acetylated by reaction with acetic anhydride. Each synthesis was done in duplicate.

Detection of the immunological reactivities of the synthesized peptides on the rods was done by ELISA as described previously (Virji $\&$ Heckels, 1989). The rods were incubated with mAbs in phosphatebuffered saline (PBS; 0.15 M-sodium chloride, 0.15 M-sodium phosphate, pH 7.2) containing $1 \%$ BSA, $1 \%$ ovalbumin and $0.1 \%$ Tween 20. After washing and reaction with goat anti-mouse IgG conjugated to horseradish peroxidase (Zymed), colour was developed using 2,2'-azino-bis(3-ethylbenzthiazoline-6-sulphonic acid) as substrate (Sigma). The solid-phase peptides were reused after bound antibody had been dissociated by sonication of the rods in $1 \%$ SDS, $0.1 \% 2$-mercaptoethanol in $0.1 \mathrm{M}$-phosphate buffer, $\mathrm{pH} 7 \cdot 2$, at $60^{\circ} \mathrm{C}$ for $30 \mathrm{~min}$. Immunological reactivity was always observed in duplicate peptides and in assays repeated on at least two occasions. 


\section{Results}

$m A b$ reactivity. The $\mathrm{mAbs}$ were tested by dot blotting against a panel of 25 gonococcal strains expressing PIA and 25 strains expressing PIB (Table 1). Greatest reactivity was seen with $\mathrm{mAb} S \mathrm{SM} 198$, which reacted with all PIB-expressing strains tested, and SM24, which reacted with $92 \%$ of PIB strains. As expected from previous studies the remaining antibodies reacted, in differing patterns, with over $30 \%$ of PIB-expressing strains (Fletcher et al., 1986). None of the antibodies reacted with PIA-expressing gonococci or with meningococci. Five PIB-expressing strains of different serotype and reactivity pattern were chosen for further study and included one of the only two PIB-expressing strains which failed to react with $\mathrm{mAb}$ SM24. The reactivity of these strains, together with strains R10 and MS11 for which the sequence of the PIB gene was available, is shown in Table 1.

Reactivity of cross-reacting $m A b s$ with peptides from strain R10. The deduced amino acid sequence of PIB from strain R10 became available on the cloning of the PIB structural gene from that strain (Gotschlich et al., 1987). To locate the epitopes recognized by the mAbs reacting with strain $\mathrm{R} 10$, a series of decapeptides spanning the entire molecule with adjacent peptides overlapping by five residues were synthesized and reacted with each of the mAbs. Antibody SM198 reacted with a single peptide corresponding to residues 106-115, whereas mAb SM24 reacted with two adjacent peptides corresponding to residues 191-200 and 196-205. No reaction was detected with the other mAbs used.
To define more precisely the epitope recognized by mAb SM198, a series of decapeptides corresponding to the region of interest, between residues 101 and 120 , were synthesized with adjacent peptides differing by a single amino acid residue. Antibody SM198 reacted with six peptides all containing the common sequence ${ }^{107}$ WESGK $^{111}$ (Fig. 1 $a$ ), defining this as the minimum epitope recognized by the antibody.

To identify precisely the epitope recognized by $\mathrm{mAb}$ SM24, a series of hexapeptides were synthesized between residues 193 and 204, together with a series of smaller peptides centred on residue 198 . Antibody SM24 reacted with five hexapeptides, all of which contained the sequence SI. Reactivity was approximately equal with the decapeptide ${ }^{196}$ TYSIPSLFVE ${ }^{205}$, the hexapeptide ${ }^{196}$ TYSIPS ${ }^{201}$ and the pentapeptide ${ }^{196}$ TYSIP ${ }^{200}$ defining this as the optimal minimum epitope (Fig. $1 b$ ). Nevertheless, significant reactivity was seen with all peptides containing SI, including the dipeptide itself (Fig. 1b). The specificity of the reaction was confirmed by synthesizing the inverted peptide 200-196, which showed no reactivity with mAb SM24.

Reaction of type-specific $m A$ Abs with peptides from strain P9. To determine the epitopes recognized by the typespecific mAbs which did not react with peptides corresponding to strain $\mathrm{R} 10$, the complete amino acid sequence of strain P9 was required. The nucleotide sequence of the PIB gene from strain P9 was determined (Butt et al., 1990) and a comparison of the predicted amino acid sequences of PIB from strains P9, R10 and MS11 is shown in Fig. 2. The three sequences show considerable homology, with significant variations being

Table 1. Properties and reactivity of anti-PIB $m A b s$

$\mathrm{mAb}$ reactivity was determined after dot blotting of whole cell suspensions on to nitrocellulose sheets.

\begin{tabular}{l}
\hline \hline \\
\hline
\end{tabular}

$*+$, Strong reaction; \pm , weak reaction; - , no reaction; $+^{a}$, weak reaction seen against whole cells of SM198 which increased significantly when cell suspensions were treated with $1 \%$ SDS before dot blotting. 

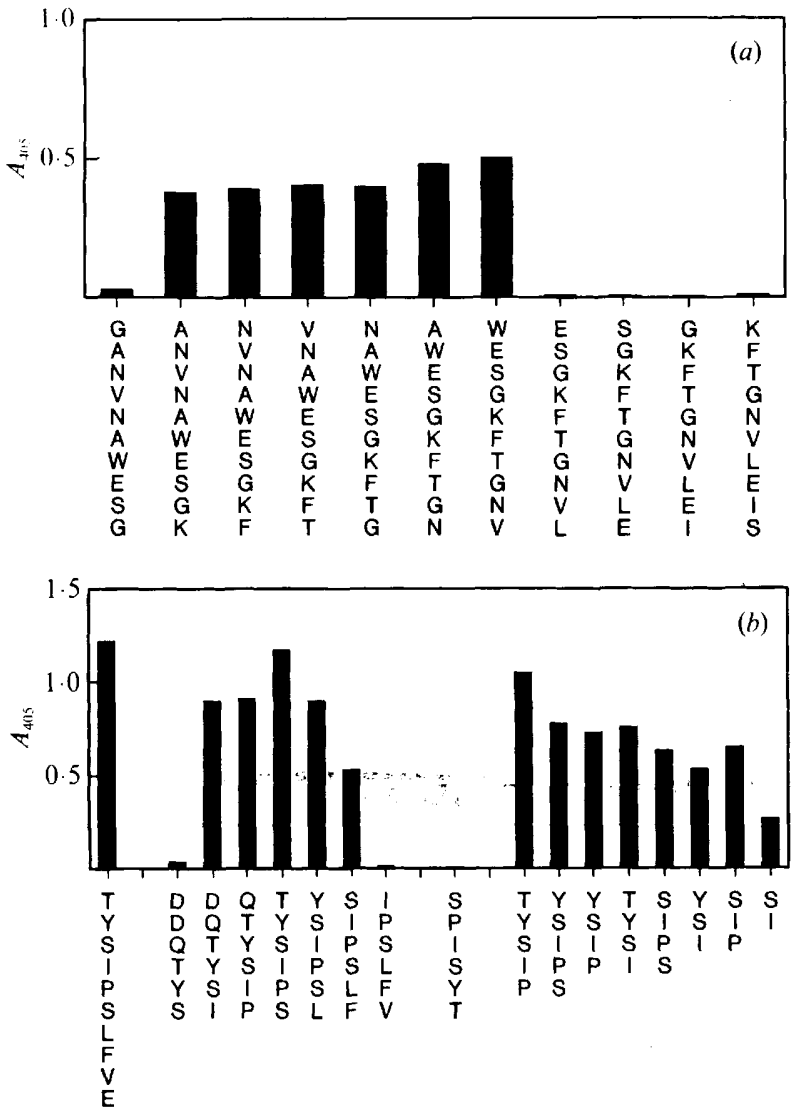

Fig. 1. Localization of epitopes recognized by cross-reacting $\mathrm{mAbs}$ SM24 and SM198. (a) mAb SM198. A series of decapeptides spanning the region between residues 101 and 120 of strain R10, with adjacent peptides differing by a single amino acid residue, were reacted in ELISA with mAb 198. (b) mAb SM24. A series of hexapeptides spanning the region between residues 193 and 204 of strain R10, together with a series of smaller peptides centred on residue 198 were reacted in ELISA with mAb SM24. The optimal decapeptide was included to permit quantitative comparison of reactivity of the smaller peptides. largely confined to two regions centred on residues 196 and 237. A series of solid-phase decapeptides were synthesized corresponding to the P9 sequence in the variable regions between amino acids $182-208$ and 227243. Each of the antibodies tested reacted with one or more peptides in the region 182-208; none of the antibodies reacted with peptides corresponding to sequences from the region 227-243. Although the degree of reactivity varied considerably between the antibodies, considerable overlap was seen in the individual peptides recognized (Fig. $3 a-d$ ). Thus, on the basis of the hexapeptides recognized, the minimum epitope recognized by both mAbs SM21 and SM203 was the hexapeptide ${ }^{192}$ YEHQVY ${ }^{197}$, while that recognized by SM22 was the heptapeptide ${ }^{190}$ IEYEHQVY ${ }^{197}$. The reactivity seen with mAb SM20 was too weak to allow confident prediction of the epitope recognized, but results implicated the heptapeptide ${ }^{192}$ YEHQVYS ${ }^{198}$.

Differences in amino acid sequences between strains and reaction of $m A$ Abs with variable peptides. The similarity in the epitopes recognized by the type-specific mAbs was somewhat surprising given their spectrum of reactivity with different strains. To investigate the effect of differences in amino acid sequences between strains on $\mathrm{mAb}$ binding, the sequence of the PIB gene between the positions coding for residues 166-250 was determined for each of the strains shown in Table 1. Two oligonucleotide primers were synthesized, one corresponding to the coding sequence for amino acids 166-173 and the other complementary to the coding sequence for amino acids 247-253. These were used as primers in the PCR, to amplify the chromosomal DNA between these positions. The amplified DNA was cloned into M13 phage and sequenced. The comparison of the deduced amino acid

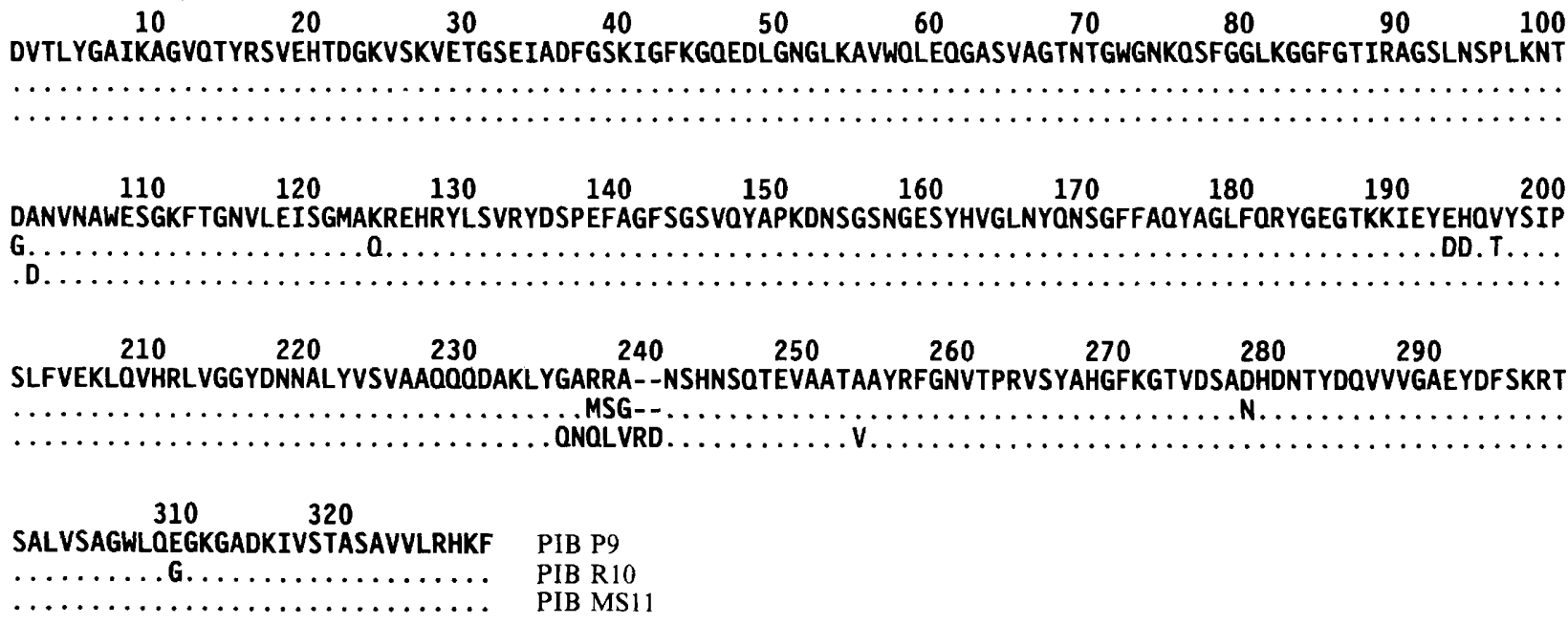

Fig. 2. Deduced amino acid sequence of PIB from strain P9 (upper sequence) aligned with PIB sequences from strains R10 (centre; Gotschlich et al., 1987) and MS11 (bottom; Carbonetti et al., 1988). Dots denote identity with the sequence of PIB from strain P9. 

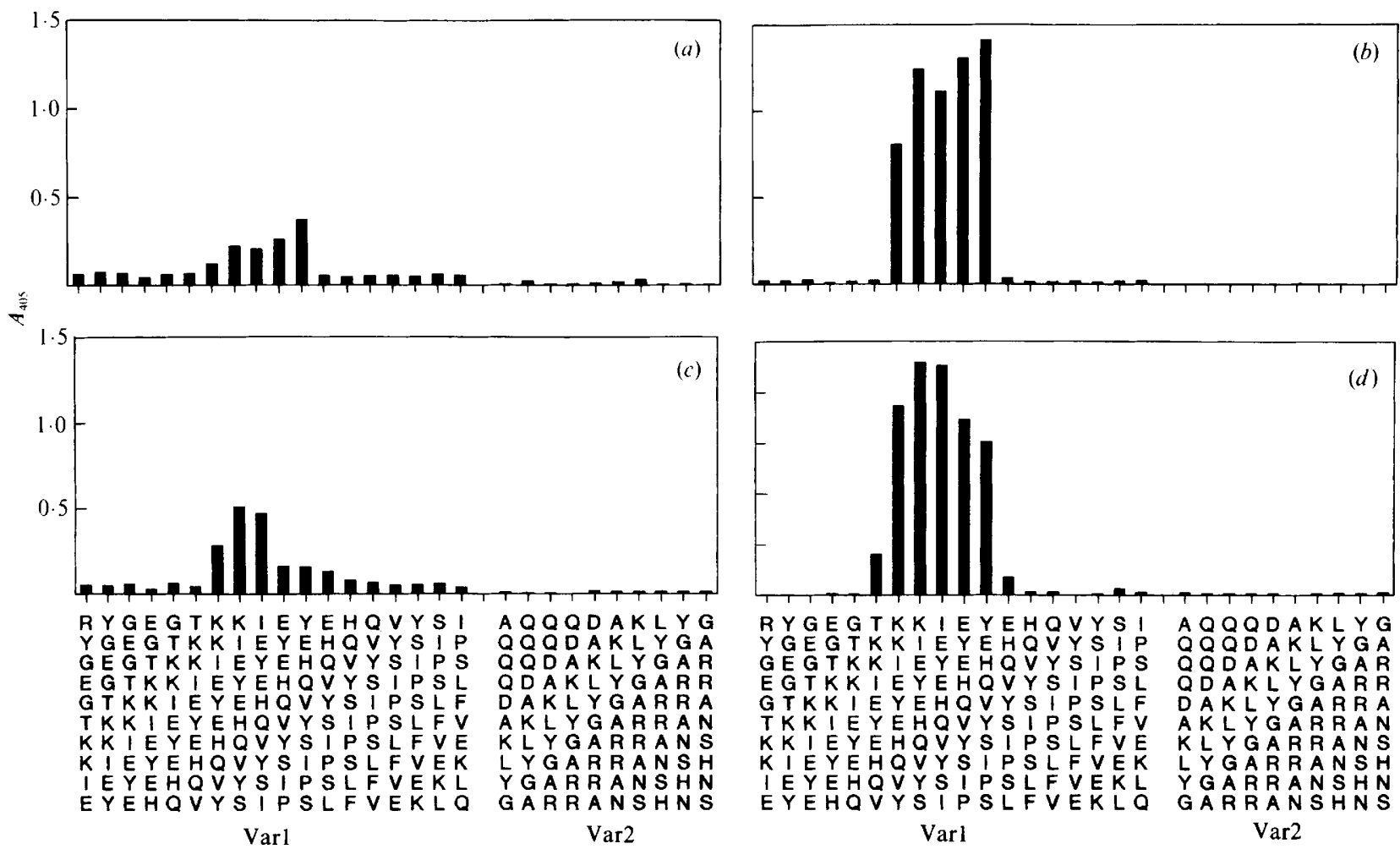
YGEGTKKI EYEHQVYSIP QQQDAKLYGA GEGTKKIEYEHQVYS IPS QQDAKLYGAR EGTKKIEYEHQVYS IPSL QDAKLYGARR GTKKIEYEHQVYS IPS LF TKKIEYEHQVYSIPSLFV KKI I YEHQVYSIPSLFVE KIEYEHOVYSIPSLFVEK IEY EHOVYS I PSLFVEK IEYEHQVYS IPSLFVEKL DAKLYGARRA AKLYGARRAN KLYGARRANS LYARRANSH YGARRANSHN Varl

$\operatorname{Var} 2$ Varl

$\operatorname{Var} 2$

Fig. 3. Localization of epitopes recognized by type-specific antibodies. A series of solid-phase decapeptides was synthesized corresponding to the $P 9$ sequence in the variable regions Varl and Var2 between amino acids 182-208 and 227-243. Adjacent peptides differed by a single amino acid residue. Peptides were reacted with the type specific antibodies SM20 (a), SM21 (b), SM22 (c) and SM203 $(d)$

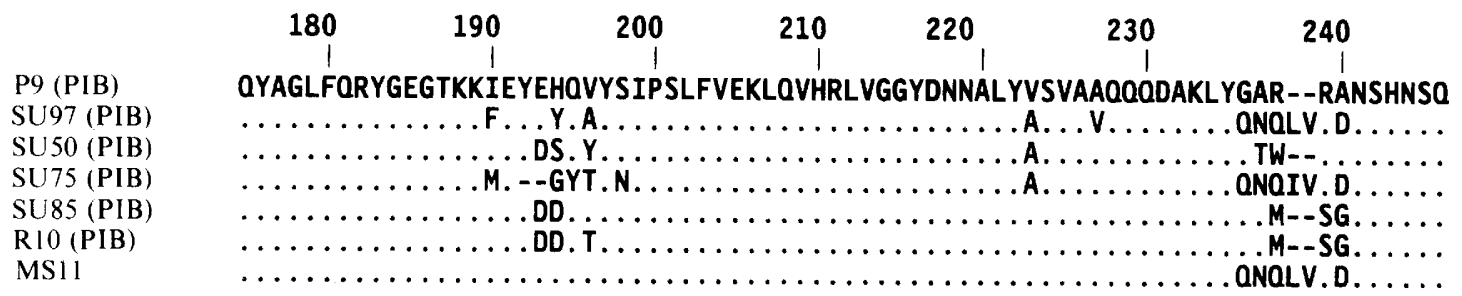

Fig. 4. Comparison of the deduced amino acid sequence between residues $166-252$ of PIB from gonococcal strains with differing $\mathrm{mAb}$ reactivity. Dots denote identity with the sequence of PIB from strain P9.

sequences determined in this way is shown in Fig. 4. Significant differences between strains were found in the two regions previously noted.

Sequence comparisons directly revealed the strain specificity of two mAbs. The putative epitope for $\mathrm{mAb}$ SM22 (IEYEHQVY) was present only in strains P9 and MS11 and only these strains reacted with the antibody. In addition, all the strains recognized by the broadly cross-reacting SM24 with the putative epitope TYSIPS contained at least the sequence YSIPS, while in the only two non-reacting strains tested this was replaced by the sequence YNIPS, reinforcing the necessary presence of the dipeptide SI. In contrast, the putative epitope (YEHQVY) recognized by mAbs SM21 and SM203 could not be confirmed by sequence comparison since it was not present in strain SU97 which reacted strongly with both antibodies.

To examine the effect of any amino acid change on the reactivity of each $\mathrm{mAb}$ a series of peptides based on the decapeptide ${ }^{191}$ EYEHQVYSIP ${ }^{200}$ and the hexapeptide ${ }^{196}$ VYSIPS ${ }^{201}$ found in strain P9 were synthesized, in which individual amino acid residues were substituted, either singly or in combination, by each of the different residues found in the other strains. Reaction of these peptides with mAbs SM21, SM24 and SM203 revealed that some amino acid substitutions had little effect on $\mathrm{mAb}$ binding while others completely abolished reactivity (Fig. 5). Substitution of $Y$ for ${ }^{194} \mathrm{H}$ or A for ${ }^{196} \mathrm{~V}$ in 

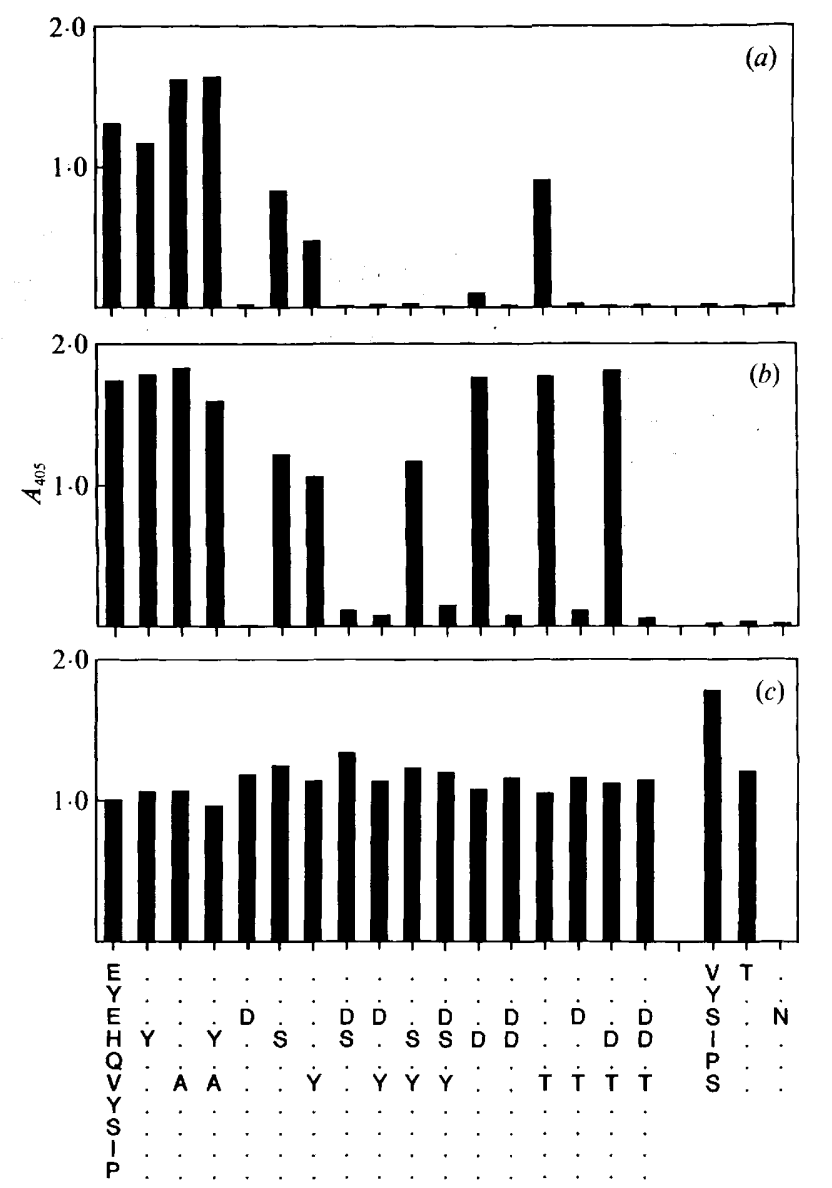

Fig. 5. Effect of amino acid replacements in the epitopes recognized by mAbs. A series of peptides based on the decapeptide ${ }^{193}$ EYEHQVYSIP ${ }^{200}$ and the hexapeptide ${ }^{196}$ VYSIPS $^{201}$ found in strain P9 was synthesized, in which individual amino acid residues were substituted, either singly or in combination, by each of the different residues found in the other strains. Peptides were reacted with mAbs SM21 (a), SM203 (b), SM24 (c).

peptide ${ }^{191}$ EYEHQVYSIP 200 had no effect on the binding of mAbs SM21 or SM203, consistent with their reactivity with the sequence found in strain SU97. The two antibodies did show differences in reactivity when other substitutions were made. Antibody SM21 also reacted with peptides containing the substitutions ${ }^{194} \mathrm{~S}$, ${ }^{196} \mathrm{Y}$ or ${ }^{196} \mathrm{~T}$ but not ${ }^{194} \mathrm{D}$, while SM203 reacted with all substitutions at either position. The reactivity of SM21 was completely abolished by the substitution of $D$ for ${ }^{193} \mathrm{E}$, consistent with its failure to react with all three strains containing this substitution. Reaction of SM203 was also abolished by the ${ }^{193} \mathrm{D}$ substitution although it did show weak reactivity with one of these strains.

Antibody SM24 reacted equally well with all of the decapeptides, in accord with its reactivity with all six strains represented by the replacement peptides. SM24 also reacted with the hexapeptide ${ }^{196}$ VYSIPS $^{201}$ and with the replacement peptide containing the substitution $\mathrm{T}$ for ${ }^{196} \mathrm{~V}$. Reactivity of SM24 was however completely abolished by the substitution $\mathrm{N}$ for ${ }^{198} \mathrm{~S}$, again consistent with its failure to react with the two strains containing this substitution.

\section{Discussion}

Comparison of the deduced primary amino acid sequence of PIB from strain P9 with those previously reported for strains R10 and MS11 confirms the considerable homology between the antigenically distinct proteins, with less than $5 \%$ sequence difference between the strains. Such homology suggests a conserved three-dimensional structure of the proteins in accord with a highly conserved functional role as a porin (Young et al., 1983; Lynch et al., 1983) and also perhaps in interactions with host cells (Blake, 1985). The similarity between the deduced amino acid sequences suggests that antigenic differences between strains must largely result from sequence variations in localized regions. The sequence alignment of the three proteins indicates two such regions centred on residues 196 (Var1) and 237 (Var2), and the variability of these regions is confirmed by the partial sequences of a further five strains.

The localization of linear epitopes recognized by mAbs has been greatly facilitated by the development of techniques for the concurrent synthesis of large numbers of peptides for testing by ELISA (Geysen et al., 1987; Virji \& Heckels, 1989). Using this technique it was revealed that five of the six mAbs tested reacted with peptides corresponding to the residues between positions 190 and 201 with the four type-specific mAbs reacting with overlapping peptides in the region 192-198 and the broadly cross-reacting mAb SM24 recognizing the sequence ${ }^{196}$ TYSIP ${ }^{200}$.

The close similarity and indeed apparent identity of the epitopes recognized by mAbs on strain P9 (Table 2) was initially surprising given the differing patterns of strain reactivity seen with the antibodies. However, analysis of the effect of amino acid substitutions reveals that additional $\mathrm{mAb}$ specificity is generated by differences in the influence of single amino acid changes on $\mathrm{mAb}$ binding. Indeed it seems likely that given the limited variation between the proteins, any scheme for serological differentiation of PI must rely on similar influences on $\mathrm{mAb}$ binding, so that antigenic differences between strains are recognized not simply by their reactivity with individual $\mathrm{mAbs}$ but rather by different patterns of reactivity with a panel of antibodies. This is precisely the situation with two schemes for the definition of serovars of PIB (Knapp et al., 1984; 
Table 2. Epitopes recognized by $m A$ bs on $P I B$

$\mathrm{X}$ denotes position within epitope where all substitutions tested reacted with antibody.

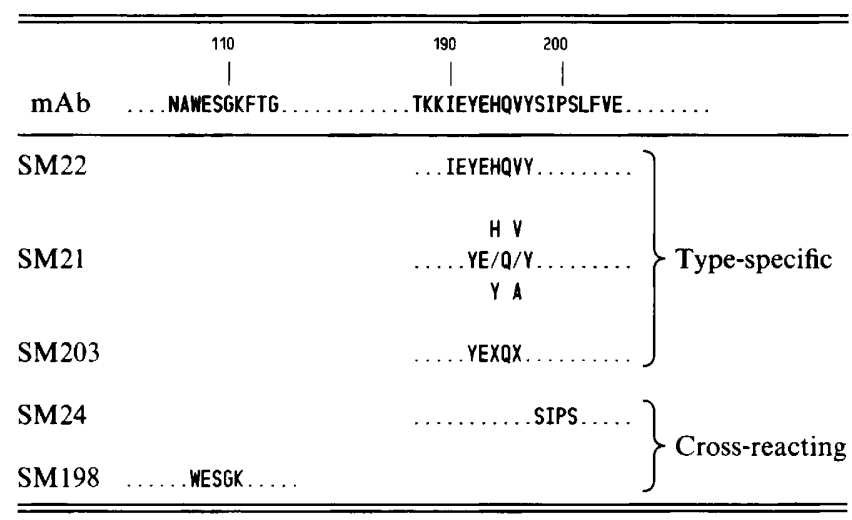

Sandstrom et al., 1985). Although in the current study each of the type-specific antibodies reacted with sequences in Varl, it would appear likely that sequence differences in Var2 could also generate epitopes with potential for serological differentiation. Indeed, this appears to be the case, since strains P9 and MS11, which belong to different serovars, have identical sequences in Varl but differ significantly in Var2. It therefore appears likely that the antigenic diversity of PIB is largely generated by sequence variation in only two discrete regions of the molecule. Despite antigenic differences between the strains, comparison of the sequences shows significant conservation of sequences in the variable regions of strains from different geographical locations. Thus strain MS11, isolated in the USA, shows homology with the British isolates strain P9 in Var1 but not in Var2 and, in contrast, with strain SU97 in Var2 but not Var1. Such mixing and matching between the two variable regions suggests that one mechanism by which genetic diversity may have arisen involved recombination events between the por genes of different strains.

In this context it is interesting to compare this situation with that of the closely related meningococcus. Meningococci express two rather than one porin proteins (Barlow et al., 1989; West \& Clarke, 1989), the class 1 and class $2 / 3$ proteins, which are responsible for serotype and subtype specificity, respectively (Frasch $e t$ al., 1985). PIB shows significant sequence homology with both proteins (Barlow et al., 1989; Murakami et al., 1989) suggesting similar organization within the outer membrane. Comparative sequence analysis and epitope mapping on the class 1 protein have also revealed two discrete variable regions, and that mixing and matching of these sequences in these regions generates two independent sero-subtype specificities in each strain
(McGuiness et al., 1990). Interestingly these meningococcal variable domains occur at quite different regions of the molecule to the variable regions on PIB.

Immunization with outer membranes (Heckels et al., 1989) or detergent micelles containing PI in its native conformation (Kersten et al., 1988; Wetzler et al., 1988) produces antibodies which are type-specific, demonstrating that the variable determinants are immunodominant. Secondary structural analysis of PIB from strain P9 shows alternating domains of hydrophilic and hydrophobic residues similar to those reported for PIA (Carbonetti \& Sparling, 1987) and typical of other outer transmembrane proteins (Vogel \& Jagnig, 1986). Thus, although several hydrophilic domains of the protein may be exposed on the bacterial surface it appears that those containing variable determinants are particularly accessible to the immune system and hence are particularly immunogenic. The surface exposure of Varl is also consistent with the ability of all the antibodies recognizing sequences within it to react with the native protein and, in addition, to cause complement-mediated bactericidal killing. In contrast, the epitope recognized by $\mathrm{mAb}$ SM198 lies in a region of low hydrophilicity, the antibody reacts only weakly with intact cells and is not bactericidal, suggesting that it is not well exposed on the surface of the gonococcus.

Antibodies to PI may be particularly important in preventing the complications associated with gonococcal infection. Bactericidal antibodies directed against PI produced in response to gonococcal salpingitis appear to protect against reinfection by strains of the same serovar (Buchanan et al., 1980). Clearly any potential vaccine should produce immunity to the widest possible range of strains. The location of the epitope, ${ }^{196}$ TYSIP $^{200}$ recognized by $\mathrm{mAb}$ SM24 is therefore of particular interest since this antibody reacts with, and is bactericidal for, $92 \%$ of PIB-expressing strains tested (Fletcher et al., 1986). Comparison of the sequences reveals the reason for the failure of this broadly cross-reacting antibody to react with two of the panel of strains, since these both contain in Varl the sequence YNIPS, which lacks the essential dipeptide at the centre of the epitope. In a previous study the SM24 epitope was shown to lie between residues 193-204 and synthetic peptide corresponding to this region 193-204 from strain R10 was used to immunize rabbits (Heckels et al., 1990). The sera obtained reacted with native PI from the homologous strains and were bactericidal for it, but showed only limited reactivity with strain $\mathrm{P} 9$. The reason for the limited cross-reactivity of the antisera raised against the peptide containing the conserved SM24 epitope is now revealed since the sera obtained showed specificity for the $\mathrm{N}$ terminus of the peptide, containing the sequence differences found in Varl, rather than the $\mathrm{C}$ terminus 
which contains the conserved epitope. Clearly, future studies with synthetic peptides will greatly benefit from the insight into the structure and immunochemistry of PIB provided by the current studies.

This work was supported by an MRC Project Grant. N.B. was in receipt of MRC Research Studentship.

\section{References}

Barlow, A. K., Heckels, J. E. \& Clarke, I. N. (1989). The class I outer membrane protein of Neisseria meningitidis: gene sequence, structural and immunological similarities to gonococcal porins. Molecular Microbiology 3, 131-139.

BLAKE, M. S. (1985). Implications of the active role of gonococcal porins in disease. In The Pathogenic Neisseriae, pp. 251-258. Edited by G. Schoolnik. Washington, DC: American Society for Microbiology.

Buchanan, T. M., Eschenbach, D. A., Knapp, J. S. \& Holmes, K. K. (1980). Gonococcal salpingitis is less likely to recur with Neisseria gonorrhoeae of the same principal outer membrane protein antigen type. American Journal of Obstetrics and Gynecology 138, 978-980.

Butt, N. J., LAMBden, P. R. \& Heckels, J. E. (1990). The nucleotide sequence of por gene encoding expression of outer membrane protein PIB in Neisseria gonorrhoeae strain P9. Nucleic Acids Research 14, 4258.

Carbonetti, N. H. \& Sparling, P. F. (1987). Molecular cloning and characterisation of the structural gene for protein I, the major outer membrane protein of Neisseria gonorrhoeae. Proceedings of the National Academy of Sciences of the United States of America 84, 9084-9089.

Carbonetti, N. H., Simmad, V. L., Seifert, H. S., So; M. \& Sparling, P. F. (1988). Genetics of protein I of Neisseria gonorrhoeae: construction of hybrid porins. Proceedings of the National Academy of Sciences of the United States of America 85, 6841-6845.

Fletcher, J. N., ZAK, K., VIRJI, M. \& HeCKels, J. E. (1986). Monoclonal antibodies to gonococcal outer membrane protein I: location of a conserved epitope on protein IB. Journal of General Microbiology 132, 1611-1620.

Frasch, C. E., Zollinger, W. D. \& Poolman, J. T. (1985). Serotype antigens of Neisseria meningitidis and a proposed scheme for designation of serotypes. Reviews of Infectious Diseases 7, 504-510.

Geysen, H. M., Rodda, S. J., Mason, T. J., TribBick, G. \& Schoofs, P. G. (1987). Strategies for epitope analysis using peptide synthesis. Journal of Immunological Methods 103, 259-274.

Gotschlich, E. C., Seiff, M. E., Blake, M. S. \& CoOmey, M. (1987). Porin proteins of Neisseria gonorrhoeae: cloning and gene structure. Proceedings of the National Academy of Sciences of the United States of America 84, 8135-8139.

HECKELS, J. E. (1977). The surface properties of Neisseria gonorrhoeae: isolation of the major components of the outer membrane. Journal of General Microbiology 99, 333-341.

Heckels, J. E., Fletcher, J. N. \& VIRJI, M. (1989). The potential protective effect of immunization with outer-membrane protein I from Neisseria gonorrhoeae. Journal of General Microbiology 135, 2269-2276

HeCKELS, J. E., VIRJI, M. \& TINSLEY, C. R. (1990). Vaccination against gonorrhoea: the potential protective effect of immunization with a synthetic peptide containing a conserved epitope of gonococcal outer membrane protein IB. Vaccine 8, 225-230.

Higgins, D. G. \& Sharp, P. M. (1988). Clustal: a package for performing multiple sequence alignments on a microcomputer. Gene 73, 237-244.

HoPP, T. P. \& WoODs, K. R. (1981). Prediction of protein antigenic determinants from amino acid sequences. Proceedings of the National Academy of Sciences of the United States of America 78, 3824-3828.

Kersten, G. F. A., Teerlink, T., Derks, H. J. G. M., VerleiJ, A. J., Van Wezel, T. L., Crommelin, D. J. A. \& Beuvery, E. C. (1988).
Incorporation of the major outer membrane protein of Neisseria gonorrhoeae in saponin-lipid complexes (Iscoms): chemical analysis, some structural features, and comparison of their immunogenicity with three other antigen delivery systems. Infection and Immunity $\mathbf{5 6}$, $432-438$.

KNaPP, J. S., Tamm, M. R. T., Nowinski, R. C., Holmes, K. K. \& SANDSTROM, E. G. (1984). Serological classification of Neisseria gonorrhoeae with use of monoclonal antibodies to gonococcal outer membrane protein I. Journal of Infectious Diseases 50, 44-48.

KYTE, J. \& DoolitTLE, R. F. (1982). A simple method for displaying the hydropathic character of a protein. Journal of Molecular Biology 157, 105-132.

LAMBden, P. R. \& HeCKels, J. E. (1979). Outer membrane protein composition and colonial morphology of Neisseria gonorrhoeae strain P9. FEMS Microbiology Letters 5, 263-265.

LYNCH, E. C., Blake, M. S., Gotschlich, E. C. \& MaUro, A. (1984). Studies of porins. Spontaneous transfer from whole cells and reconstituted porin proteins of Neisseria gonorrhoeae and Neisseria meningitidis. Biophysics Journal 45, 104-107.

McGuinness, B., Barlow, A. K., Clarke, I. N., Farley, J. E., Alinionis, A., Poolman, J. T. \& Heckels, J. E. (1990). Deduced amino acid sequences of class 1 protein (PorA) from three strains of Neisseria meningitidis: synthetic peptides define the epitopes responsible for serosubtype specificity. Journal of Experimental Medicine 171, 1871-1882.

MuraKami, K., Gotschlich, E. C. \& SeifF, M. E. (1989). Cloning and characterization of the structural gene for the class 2 protein of Neisseria meningitidis. Infection and Immunity 57, 2318-2323.

Sandstrom, E. G., Chen, K. C. S. \& Buchanan, T. M. (1982). Serology of Neisseria gonorrhoeae: co-agglutination serogroups WI and WII/III correspond to different outer membrane protein molecules. Infection and Immunity 38, 462-470.

Sandstrom, E., Lindell, P., Harfast, B., Blomberg, F., Ryden, A.-C. \& Bygdeman, S. (1985). Evaluation of a new set of Neisseria gonorrhoeae serogroup W-specific monoclonal antibodies for serovar determination. In The Pathogenic Neisseriae, pp. 26-30. Edited by G. K. Schoolnik, Washington, DC: American Society for Microbiology.

VIRI, M. \& HeCKeLS, J. E. (1989). Location of a blocking epitope on outer-membrane protein III of Neisseria gonorrhoeae by synthetic peptide analysis. Journal of General Microbiology 135, 1895-1899.

VIRJI, M., ZAK, K. \& HeCKels, J. E. (1986). Monoclonal antibodies to gonococcal outer membrane protein IB: use in the investigation of the potential protective effect of antibodies directed against conserved and type-specific epitopes. Journal of General Microbiology 132, 1621-1629.

ViRJ, M., Fletcher, J. N., ZaK, K. \& Heckels, J. E. (1987). The potential protective effect of monoclonal antibodies to gonococcal outer membrane protein IA. Journal of General Microbiology 133, 2639-2646.

VoGEL, H. \& JAHNIG, F. (1986). Models for the structure of outer membrane proteins of Escherichia coli derived from Raman spectroscopy and prediction methods. Journal of Molecular Biology 190, 191-199.

West, S. E. H. \& Clarke, V. L. (1989). Genetic loci and linkage associations in Neisseria gonorrhoeae and Neisseria meningitidis. Clinical Microbiology Reviews 2, S92-S103.

Wetzler, L. M., Blake, M. S. \& Gotschlich, E. C. (1988). Characterization of antibodies raised to protein I (PI) of Neisseria gonorrhoeae by injection with PI-liposome constructs. In Gonococci and Meningococci, pp. 457-463. Edited by J. T. Poolman, H. C. Zanen, T. F. Meyer, J. E. Heckels, P. R. H. Mäkelä, H. Smith \& E. C. Beuvery. Dordrecht: Kluwer Academic Publishers.

Young, J. D.-E., Blake, M., Mauro, A. \& Cohen, Z. A. (1983). Properties of the major outer membrane protein from Neisseria gonorrhoeae incorporated into model lipid membranes. Proceedings of the National Academy of Sciences of the United States of America 80 , 3831-3835.

ZaK, K., DiaZ, J.-L., JACKson, D. \& Heckels, J. E. (1984). Antigenic variation during infection with Neisseria gonorrhoeae: detection of antibodies to surface proteins in sera of patients with gonorrhoea. Journal of Infectious Diseases 149, 166-173. 